\title{
Discurso e Políticas Ambientais Brasileiras e Bolivianas Aplicadas a Grandes Obras Infraestruturais ${ }^{(\bullet)}$
}

\author{
Brazilian and bolian Speech end Environmental Policies Applied to \\ LARGE INFRASTRUCTURAL WORKS
}

\author{
Suzana Cristina LourençO(*) \\ Luciana Riça Mourão Borges ${ }^{(*)}$
}

Resumo: Lançando mão da premissa que as relações políticas e econômicas se expressam no território e nos biomas nele inseridos, o presente artigo procurou contrastar as diferentes realidades de políticas públicas ambientais entre Brasil e Bolívia, traçando os pontos de convergência e analisando como estas se relacionam com o discurso da Iniciativa para a Integração da Infraestrutura Regional Sul-Americana (IIRSA). Conclui-se que a estrutura política ambiental em ambos os países não é favorável à participação social nos processos decisórios ambientais, aumentando os conflitos socioambientais.

Palavras-chave: IIRSA. Desenvolvimento sustentável. Políticas ambientais.

\begin{abstract}
Integrity, cohesion and spatial organization of territories are made by the States and kept by legal institutions, executive, military and political negotiations. Cohesion and spatial structure, in turn, define States' interventions. This article contrasts different realities of environmental public policies between Brazil and Bolivia, recognizing the points of convergence between them and analyzing how they are related to the discourse of the Initiative for the Integration of Regional Infrastructure in South America (IIRSA). We conclude that environmental policy structure in both countries brings down participation of social society and increases socioenvironmental conflicts.
\end{abstract}

Keywords: IIRSA. Suistanable development. Environmental policies.

• Este estudo é uma revisitação e aprofundamento teórico-empírico do Capítulo 2 da dissertação de mestrado intitulada Transfronteira Brasil-Bolivia: Desenvolvimento Sustentável na Iniciativa de Integração Regional Sul-americana, Eixo Peru-Brasil e Bolivia, apresentado ao Programa de Pós-Graduação em Integração da América Latina (PROLAM) da Universidade de São Paulo em agosto de 2011. Detivemo-nos mais centradamente na relação política entre o Brasil e a Bolívia e a participação da sociedade civil neste processo.

(*) Mestre pelo Programa de Pós-Graduação em Integração da América Latina (PROLAM) da Universidade de São Paulo, São Paulo, Brasil. E-mail: <suzanalourenco@yahoo.com.br>.

(**) Mestre pelo Programa de Pós-Graduação em Geografia Humana (PPGH) da Faculdade de Filosofia, Letras e Ciências Humanas da Universidade de São Paulo (FFLCH/USP), São Paulo, Brasil.Email: lucianarmborges@gmail.com. Recebido em 16.09.2012 e aceito em 17.10.2012. 


\section{A política ambiental brasileira aplicada aOS projetos infraestruturais}

Apesar do histórico agrário e extrativista que perpassa a realidade brasileira desde a colonização, a necessidade da preservação ambiental se torna explícita nas leis e propostas de integração internacional somente após os regimes ditatoriais. A Constituição Brasileira de 1988 solidifica — ao menos na redação da lei — a conduta de preservação dos recursos naturais (Organização do Estado, Capítulo I: da organização político-administrativa, Capítulo III: da política agrícola e fundiária e da reforma agrária, Capítulo VI: do meio ambiente), bem como na garantia como direito fundamental das sociedades que compõem o Estado. Apesar da preocupação, o conceito de desenvolvimento sustentável ou a noção de natureza na Constituição brasileira ainda não aparecem tão bem interiorizados quanto em outros Estados latino-americanos, como Bolívia e Equador, expoentes sul-americanos em experimentações de modelos democráticos.

A partir dos anos 90, quando o Brasil inicia seu projeto de afirmação internacional por meio da defesa dos direitos humanos e da natureza, apagando assim a imagem repressiva do Estado deixado pelos governos anteriores, a discussão sobre a conservação dos recursos naturais para as próximas gerações passa a tomar vulto internamente. Há um aumento significativo no número de organizações da sociedade civil ${ }^{(1)}$ e desenvolvimento das instituições do Estado voltado para a proteção socioambiental. Porém, a complexidade das relações políticas e instâncias decisórias acabam por conformar uma estrutura de poder que nem sempre leva a uma proposta de política eficaz e eficiente. Os discursos de sustentabilidade acabam por viabilizar grandes obras e planos governamentais sob a alcunha de uma relação harmônica com o ambiente.

A legislação brasileira é uma das melhores do mundo, em relação ao desenvolvimento e às obras infraestruturais. O problema maior não é, entretanto, sua existência, senão sua aplicabilidade: há um embate entre aquilo que seria a sustentabilidade ambiental dos recursos a partir dos empreendimentos e as demandas nacionais ${ }^{(2)}$.

O Ministério do Meio Ambiente brasileiro, Órgão Executivo de máxima responsabilidade em gestão de meio ambiente no país, surgiu quatro meses após a Cúpula da Terra, em novembro de 1992 e teve sua estrutura regimental recentemente regulamentada pelo Decreto nำ 6.101, de 26 de abril de 2007.

A Política Nacional de Meio Ambiente se expressa pelo Sistema Nacional de Meio Ambiente (SISNAMA). Este define como serão delineadas as políticas ambientais e como estas expressarão a(s) realidade(s) nacional(is). Envolve, no processo decisório, um conjunto de atores sociais com distintas projeções no cenário político nacional (expresso no artigo 5ํ do Decreto nำ 99.274 de 1990). Contudo, as representações governamentais

(1) Para um aprofundamento sobre o conceito de sociedade civil, ressaltamos Bobbio (1982).

(2) Entrevista concedida por Dorisvalder Nunes, Docente e Pesquisador do curso de Geografia na Universidade Federal de Rondônia, o qual participou de reuniões e processos de licenciamento ambiental das Hidroelétricas de Jirau e Santo Antônio. Data da entrevista: 12 de julho de 2010. 
que legislam pelo meio ambiente e pelos projetos pautados na sustentabilidade têm dificuldade em sintonizar seu discurso sobre desenvolvimento sustentável, o que leva a uma disparidade de opiniões refletidas na multiplicidade de medidas provisórias e decretos de lei nos âmbitos municipal, estadual e nacional. Como não há uma coerência entre as leis aprovadas, a aplicabilidade de medidas socioambientais é comprometida a nível nacional.

Cabe ressaltar ainda o enfraquecimento da representação da sociedade civil nos processos decisórios, não por sua ausência, mas por seu enfraquecimento financeiro que acarreta um enfraquecimento político. Como mostra a figura 1, geralmente, a sociedade civil padece de recursos financeiros para suas mobilizações e deslocamentos das regiões à capital nacional, onde comumente acontecem as reuniões decisórias. Isso é agravado pelo perfil ideológico das organizações (figura 2), que nem sempre é o principal tema da agenda governamental vigente, ainda que seja um tema importante em termos socioambientais.

Enquanto estrutura institucional voltada para a questão socioambiental, o Estado brasileiro pode ser definido como compartimentada: os diálogos interministeriais e intersecretarias se dão de maneira ora incipiente, ora inexistente, o que dificulta a tomada de decisões políticas. Há um diálogo mais fluido entre as instituições governamentais e o setor privado que uma representatividade do Estado à sociedade.

\section{ASSOCIADAS SEGUNDO O VALOR DO ORÇAMENTO POR FAIXA E ANOS (\%)}

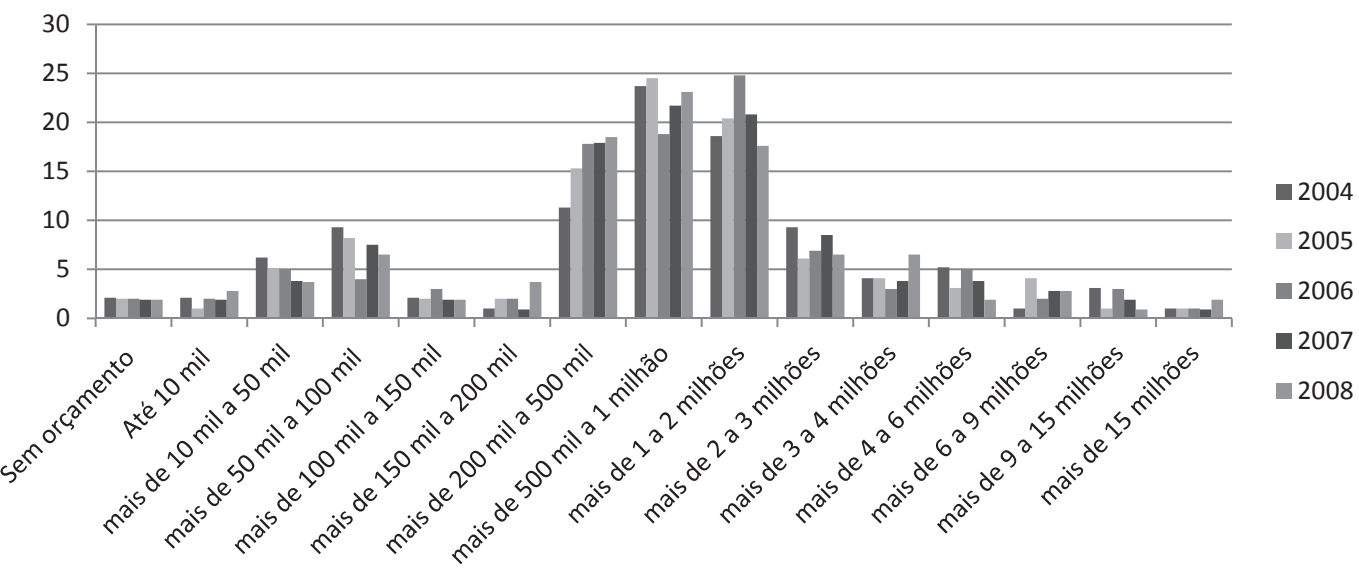

Figura 1: Perfil orçamentário das OSCs no Brasil. Nota-se que mais da metade das OSCs nacionais situam-se nos padrões médios orçamentários. Adaptado de ABONG, 2010. 
PRINCIPAIS VOCALIZAÇÕES POLITICAS NACIONAIS

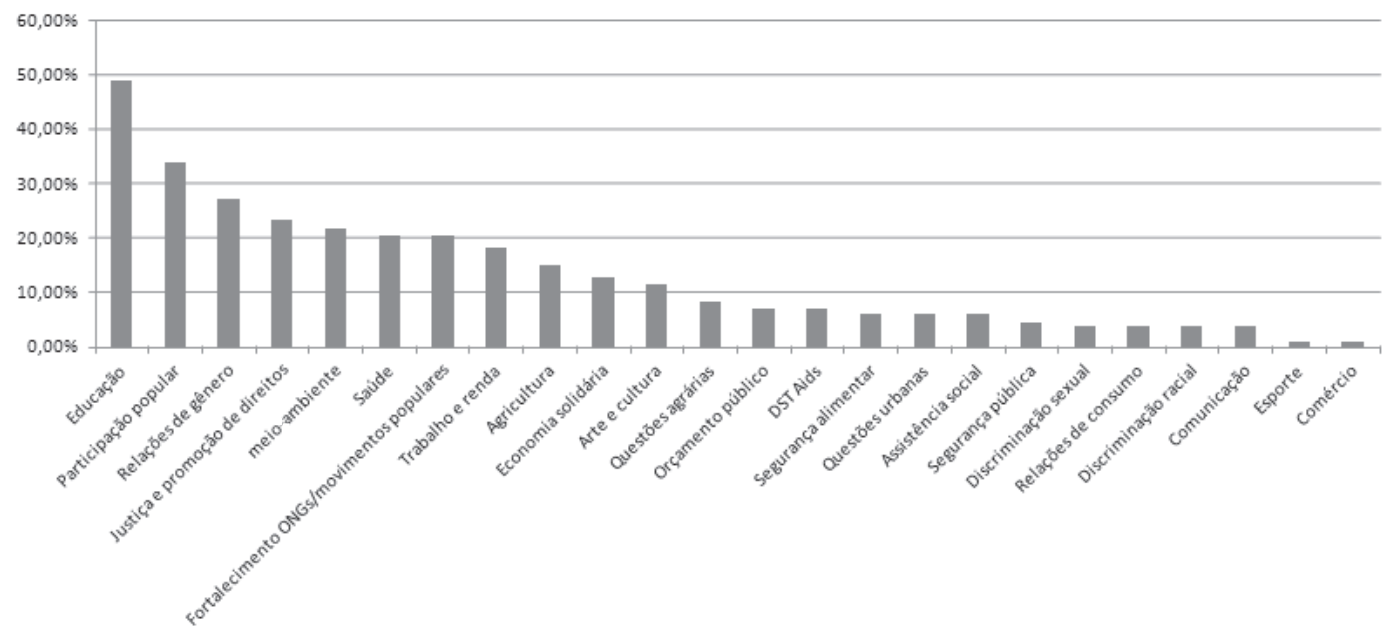

Figura 2: Principais atuações políticas das OSCs Nacionais. Além das causas relacionadas a políticas públicas, nota-se o desenvolvimento de OSCs destinadas a intervir pela causa das outras OSCs. Adaptado de Gouveia, 2010.

Esta ambiguidade de posicionamentos em relação ao meio ambiente se expressa no Grupo 3 das obras da IIRSA (Corredor Fluvial Madeira - Madre de Dios - Beni, onde se situam a Hidrelétrica de Jirau e Santo Antônio) vinculada ao mesmo Eixo no qual estão inseridas as obras de construção do Grupo 2 do Eixo Peru-Brasil-Bolívia.

Cabe contextualizar que se compõe um contexto político e econômico remanescente do final do século XIX, em que surgiu pela primeira vez de modo institucionalizado a tentativa de se integrar o Brasil à Bolívia. Naquele período, existia o objetivo estatal de bem delimitar suas fronteiras e abrir caminhos à colonização e defesa do próprio território. As relações políticas e econômicas entre os dois países se submeteram ao Tratado de Petrópolis ${ }^{(3)}$ com a Bolívia, derivando daí a construção da Estrada de Ferro Madeira-Mamoré para escoamento da produção boliviana via territórios brasileiros até o oceano Atlântico. As tentativas de integração sul-americanas daquela época remetem-se à investigação das tentativas de hoje, tal como o surgimento da Iniciativa para a IIRSA, com seus eixos rodoviários, hidroviários e ferroviários (BORGES, 2012).

(3) O Tratado foi assinado em 17 de novembro de 1903 com a Bolívia, em que ao Brasil ficou a incumbência da construção da estrada de ferro que viabilizaria o transporte de pessoas e mercadorias bolivianas por território brasileiro até o oceano Atlântico, uma vez que aquele país perdeu sua saída para o oceano Pacífico para o Chile. Esse mesmo Tratado também formalizou a anexação de parte do então território boliviano que hoje constitui o estado do Acre (DOMINGUES, 2010; MARTINS JUNIOR, 2001; BRASIL, 2003). A saber, "(...) O Brasil obriga-se a construir por si ou por empresa particular, desde a $1^{\underline{a}}$ cachoeira do rio Mamoré, que é a de Guajará-Mirim, até a de Santo Antônio, no rio Madeira, do lado oriental desses rios, uma ferrovia, concedendo à Bolívia as facilidades declaradas no Tratado que se concluiu no Rio de Janeiro (...)" (TOCANTINS, 1979, p. 259). 
Faz-se referência a uma região de fronteira, com perspectivas de grande avanço do capital tanto da construção civil e energia, quanto da agroindústria, onde este último se faz mais presente com as expectativas de barateamento das exportações por meio do oceano pacífico, uma vez que a rodovia Interoceânica (que constitui um projeto da IIRSA, a chamada "Saída para o Pacífico" via Peru) já está pronta e com a construção de eclusas na usina de Jirau, a navegação via noroeste do continente sul-americano também será possibilitada (BORGES, 2012).

Hoje, a interconectividade das obras de ambos os grupos de projetos visa o escoamento da produção de minérios e soja, principalmente. Todavia, as obras vêm recebendo diversas críticas pelos movimentos sociais das comunidades locais (sobretudo ribeirinhos e indígenas) e também pelo movimento ambientalista.

Há ainda o projeto de mais uma hidrelétrica na fronteira com a Bolívia, na Cachoeira Esperança. "A lógica que está por trás de tudo é essa, não a de gerar energia para conter o apagão. Está ligada a muitos outros interesses, inclusive o mineral." Incorporada a todos esses projetos de integração, está a saída para o Pacífico, com conclusão em 2011, ligando o Brasil ao Peru por via terrestre. Nesse contexto, além das populações tradicionais em geral, em específico os indígenas terão seus territórios ameaçados em razão da disputa de interesses pela utilização dos recursos naturais. Há também o caso de populações indígenas isoladas na região de construção das hidrelétricas, que deveriam ser um motivo para o embargo das obras. Ao contrário, pressionadas pelas corporações privadas envolvidas, as esferas governamentais flexibilizam cada vez mais a legislação. "É preciso entender todo esse cenário, pois não está em jogo o Madeira pelo Madeira, e sim toda a Amazônia (...)."(4)

Conduzidas pela Empresa Camargo Corrêa, as obras das hidrelétricas de Jirau, sobretudo, vêm encarando diversas manifestações populares contra seu processo de estabelecimento. Em outubro de 2010, "indígenas e afro-descendentes que residem em comunidades quilombolas localizadas às margens do Rio Madeira se estabeleceram no local onde está sendo construída a Usina Hidrelétrica de Jirau" (SALINA, 2010). "A alegação principal por parte das comunidades foi o não recebimento das indenizações prometidas e a dificuldade de ter acesso aos rios para a prática da pesca, principal forma de subsistência destas comunidades." (SALINA, 2010) Apesar de haver sido emitida a licença de operação das obras e do ritmo acelerado, vários processos tramitam na Assembleia Legislativa de Rondônia e nos Ministérios Públicos Estadual e Federal ${ }^{(5)}$.

(4) Trecho da entrevista realizada com o presidente do Instituto Madeira Vivo, Iremar Antônio Ferreira, pelo Correio da Cidadania, publicada em 25 de agosto de 2008 com o título "Lobbies impõem usinas do Madeira em detrimento da natureza e da população". Disponível em: <http://www.mmdc.com.br/?p=2 10> Acesso em: 28 de abr./2012.

(5) Em 2009, o consórcio construtor da usina de Jirau recebeu também duas multas consecutivas, em menos de quinze dias, sendo a primeira de $\mathrm{R} \$ 475$ mil por desmatamento não licenciado e a segunda de $\mathrm{R} \$ 950$ mil por construção de barramento (ensecadeira) no rio sem a licença ambiental. Cerca de onze toneladas de peixes morreram no lago de Santo Antônio entre 2008 e 2009, na construção da ensecadeira da usina. A autuação é de 19.01.2009, pelo processo 1.31.000.000054/2009-90 do Ministério Público Federal (ZAGALLO e LISBOA, 2011,p. 35). Informação complementar em: <http://www.globoamazonia.com/Amazonia/0,,MUL933909-16052,00-CONSTRUCAO+DE+USINA+NO+RIO+ MADEIRA+CAUSA+MORTE+DE+TONELADAS+DE+PEIXES.html e http://www.capitaldojerico.com/noticias/meio-a mbiente/1321/c onstrucao-de-usina-no-rio-madeira-causa-morte-de-11-tonelad.html> Acesso em: 10 de jul./2012. 
Ênfase deve ser dada à forma de condução dos licenciamentos: as audiências públicas - que foram majoritariamente negadas por parte da população envolvida para as obras infraestruturais do Programa de Aceleração do Crescimento (PAC), no seu eixo Infraestrutura Logística e Energética em sua primeira edição (2007-2011) — legitimam os licenciamentos não pelo conteúdo do que foi tratado na audiência, mas pelas listas de presença dos participantes.

As esferas federal, estadual e municipal mergulharam na campanha de convencimento da população sobre os numerosos benefícios que iriam surgir em Rondônia e região. As pessoas que discordavam, e discordam, na realidade não possuem espaço para argumentos, sendo "(...) silenciadas ou tratadas como inimigas do progresso ou cooptadas com generosos contratos. As audiências públicas serviram apenas como uma capa de legalidade"(6).

O problema de representatividade se agrava quando a participação popular na audiência, em si, é entendida, para fins de licenciamento, como que estando todas as representações que se deslocaram à reunião de acordo com as obras, independentemente se no conteúdo das memórias e atas das reuniões conste um posicionamento negativo das sociedades envolvidas.

No que diz respeito à arena política e às instituições com direito a voto no Conselho Nacional do Meio Ambiente (CONAMA), a estrutura de representações governamentais que votam nas propostas de políticas incluem: o Ministro de Estado do Meio Ambiente que preside as plenárias onde as decisões serão votadas, assistido por seu Secretário Executivo; um representante do Instituto Brasileiro do Meio Ambiente e dos Recursos Naturais Renováveis (IBAMA) e um da Agência Nacional de Águas (ANA); um representante de cada um dos Ministérios do Governo, das Secretarias da Presidência da República indicados por seus titulares; um representante de cada um dos Governos Estaduais e do Distrito Federal, indicados pelos respectivos governadores; e oito representantes dos Governos Municipais que possuam órgão ambiental estruturado e Conselho de Meio Ambiente com caráter deliberativo.

A participação das representações de entidades de trabalhadores e da sociedade civil nas planárias perfaz um total de vinte e um votantes, sendo:

\footnotetext{
Houve também a emissão pelo Ministério Público de Rondônia e o Ministério Público Federal do Termo de Ajustamento de Conduta - Usina Hidrelétrica Santo Antônio, pelo Inquérito Civil Público n. 1.31.000.000054/2009-90, em que "(...) a Santo Antônio concorda com a celebração deste Termo de Ajustamento de Conduta, mas não reconhece qualquer culpa ou responsabilidade pelos eventos discutidos neste inquérito civil público (...)" e "(..) a empresa se compromete a apresentar um projeto de reposição de 150.000 (cento e cinquenta mil) peixes, bem como o cronograma de execução, no prazo de 6 (seis) meses, a contar desta data (...)".

(6) Trecho da entrevista realizada com o Prof. Dr. Ari Miguel Teixeira Ott, professor da Universidade Federal de Rondônia, pelo Instituto Humanitas Unisinos concedida por e-mail, publicada em 21 de março de 2012 com o título "Complexo hidrelétrico do rio Madeira: A energia gerada pelas usinas não se destina à região". Disponível em: <http://www.ihu. unisinos.br/entrevistas/complexo-hidreletrico-do-rio-madeira-entrevista-especial-com-ari-miguel-teixeira-ott/507555complexo-hidreletrico-do-rio-madeira-en trevista-especial-com-ari-miguel-te ixeira-ott> Acesso em: 28 de abr./2012.
} 
- dois representantes de entidades ambientalistas de cada uma das Regiões Geográficas do País; um representante de entidade ambientalista de âmbito nacional; três representantes de associações legalmente constituídas para a defesa dos recursos naturais e do combate à poluição, de livre escolha do Presidente da República; um representante de entidades profissionais, de âmbito nacional, com atuação na área ambiental e de saneamento, indicado pela Associação Brasileira de Engenharia Sanitária e Ambiental ABES; um representante de trabalhadores indicado pelas centrais sindicais e confederações de trabalhadores da área urbana (Central Única dos Trabalhadores - CUT, Força Sindical, Confederação Geral dos Trabalhadores - CGT, Confederação Nacional dos Trabalhadores na Indústria - CNTI e Confederação Nacional dos Trabalhadores no Comércio - CNTC), escolhido em processo coordenado pela CNTI e CNTC; um representante de trabalhadores da área rural, indicado pela Confederação Nacional dos Trabalhadores na Agricultura - CONTAG; um representante de populações tradicionais, escolhido em processo coordenado pelo Centro Nacional de Desenvolvimento Sustentável das Populações Tradicionais - CNPT/IBAMA; um representante da comunidade indígena indicado pelo Conselho de Articulação dos Povos e Organizações Indígenas do Brasil - CAPOIB; um representante da comunidade científica, indicado pela Sociedade Brasileira para o Progresso da Ciência - SBPC; um representante do Conselho Nacional de Comandantes Gerais das Polícias Militares e Corpos de Bombeiros Militares - CNCG; um representante da Fundação Brasileira para a Conservação da Natureza — FBC ${ }^{(7)}$.

A representatividade das instituições do Governo nas plenárias das decisões do MMA supera a representatividade da sociedade civil, de tal maneira que - estabelecidos os interesses dos primeiros e dicotomizados das demandas dos segundos - o panorama para a aprovação de medidas pende mais para os interesses defendidos pelo Estado que para a sociedade civil.

É expressivo, no contexto da arena política e entre os tomadores de decisão, um conflito entre o desenvolvimento e a proteção ambiental. Em verdade, a discussão seria anterior, pois já é em si uma discussão a questão de como compatibilizar o crescimento econômico a um desenvolvimento socioeconômico ecologicamente sustentável. Esses conflitos ideológicos - marcados pela dicotomia entre ser humano, sociedade e natureza - refletiram-se no discurso das políticas públicas ambientais.

A consequência dessa emergência de ações e do conflito ideológico entre os atores políticos e empresariais que decidem as leis e sua forma de aplicação é sentida tanto socialmente quanto ambientalmente, apesar do EIA/RIMA consolidado:

(...) Algumas comunidades próximas que não tinham estes acontecimentos tipo estupro, assassinato, esses problemas que ocorrem quando você tem um aumento na população

(7) Decreto CONAMA n. 3.942, de 2001. 
muito rápido e a gente não tinha estes noticiários e hoje tem. Então são coisas que acontecem que as informações não são divulgadas: manifestações de funcionário. Inclusive os noticiários não mostram isso. Então você tem uma divulgação das ações, (...) oferecimento de cursos ou investimentos que tão fazendo na cidade, mas a própria mídia não mostra os problemas que se tem. Com as explosões teve uma mortandade de peixes e a TV não mostrou, funcionários que reivindicam melhores salários, uma muvuca que eles fazem ao ponto de trancar a estrada, quebrar ônibus, a televisão não mostra. Então você tem essa parte negativa abafada. ${ }^{(8)}$

A implementação das obras dos Grupos 2 e 3 do Eixo Peru-Brasil-Bolívia tem causado muitos impasses entre a população receptora das propostas, principalmente pelas repercussões que essas obras têm trazido às cidades, aos ecossistemas e às sociedades nela presentes. Não há planos de amortização dos impactos ambientais claramente desenvolvidos ou uma planificação urbana para evitar os problemas sociais pela alta migração que vêm sofrendo, por exemplo, cidades como Porto Velho, no Brasil ou Guayaramerín e Riberalta na Bolívia.

Juntamente com a construção dessas infraestruturas, há uma intensa atração populacional. O processo de migração ocorre com a contratação de milhares de operários — para as obras —, com os demais sujeitos que migram buscando também novas oportunidades, os agentes econômicos e políticos das empresas relacionadas às construções, os próprios empresários, os agentes da especulação imobiliária e da construção civil, os industriários e comerciantes, entre outros atores sociais (BORGES, 2012).

Os diversos eventos de inundação pelas obras, extração ilegal de minérios, aumento da violência urbana e no campo não têm sido levados a conhecimento público, a fim de evitar uma manifestação da opinião pública contra as obras. O conflito no âmbito político pode ser sentido entre o Ministério do Meio Ambiente e outros órgãos que fomentam a proteção da natureza e a conservação dos recursos naturais. Os órgãos do governo intervenientes no Ministério do Meio Ambiente podem ter, inclusive, suas próprias comissões ambientais internas (como ocorre no Ministério dos Transportes, o qual tem sua própria Comissão Permanente de Meio Ambiente), nem sempre operativas, mas que aumentam o número de elementos dispersivos à consolidação de um discurso ambiental comum no plano Federal, criando condições para a exploração de áreas nas quais coincidem com os recursos naturais a serem protegidos (BECKER, 2005).

No que diz respeito aos processos de licitação das obras federais de infraestrutura, ocorre um leilão no qual as empresas construtoras apresentam seus projetos e orçamentos previstos das obras ao Governo Federal. Participam grandes empresas, com alto poderio de capital para concorrer com empresas menores: uma empresa que chama para si esse investimento tem a premissa de que algum dia ela possa estar à frente deste empreendimento, trazendo outras empresas para compor o consórcio. ${ }^{(9)}$

Concedida a licitação à empresa, esta tramita junto no órgão ambiental responsável pela licença prévia para as obras (no caso de obras de âmbito nacional, o IBAMA). Esta licença é concedida mediante, primeiramente, a consolidação de um Estudo de Impacto Ambiental

(8) Entrevista concedida por Dorisvalder Nunes, Docente e Pesquisador do curso de Geografia na Universidade Federal de Rondônia, o qual participou de reuniões e processos de licenciamento ambiental das Hidroelétricas de Jirau e Santo Antônio. Data da entrevista: 12 de julho de 2010.

(9) Idem. 
(EIA), a formulação de um Relatório de Impacto Ambiental baseado neste estudo (RIMA). Este relatório é feito por um engenheiro contratado pela empresa construtora, submetido à apreciação do IBAMA e às audiências públicas, onde se discute a viabilidade do projeto, que deveria ser interdisciplinar.

Se o projeto apresentado pela empresa e o EIA RIMA passarem pela fase de análise da proposta pelo IBAMA e pelas audiências públicas, recebe a Licença Prévia. Segundo a Lei Estadual MS n. 2.257 e a Resolução CONAMA n. 237, esta tem um prazo de cinco anos prorrogáveis. Logo, a empresa deve tramitar a Licença de Instalação (válida por seis anos prorrogáveis) e, posteriormente, Licença de Operação (4 a 10 anos de duração).

A empresa tem autorização do governo, ganhou a licitação, ou seja, a concessão de construção do empreendimento, mas (...) em havendo algum tipo de dano ambiental, social, cultural, é sua responsabilidade promover a ação mitigadora necessária para sanar aquele problema. Cabe ao governo fazer o monitoramento e a fiscalização dessas ações inclusive em relação ao próprio passivo ambiental. (...) O problema está na diretriz que vem de cima pra baixo (...). Então mesmo que não se enquadrasse, o empreendimento ia sair. (...) No caso de você fazer correção de trajetória quando há algum problema a empresa é responsabilizada mediante fiscalização dos órgãos responsáveis. Nesse caso o IBAMA a SEDAM ou a SEMA. (...)

As empresas construtoras envolvidas tanto no Grupo 2 quanto no Grupo 3 do Eixo Peru, Brasil e Bolívia baseiam as medidas de intervenção e controle de danos ambientais nas diretrizes impostas pela fiscalização do IBAMA. Apesar da influência das audiências públicas na licitação dos projetos, há uma tendência de omissão das informações sobre os impactos negativos ao meio ambiente à sociedade civil. A falta de circulação de tais informações, em regiões isoladas, influencia na decisão das audiências públicas por desconhecimento da população dos fatos ambientais negativos que acontecem em seu entorno. O conteúdo, muitas vezes inteligível à população, dos Estudos de Impacto Ambiental favorece que as populações acreditem que as medidas propostas pelo governo não lhes afetará socioeconômica e ambientalmente.

(...) Se há algum problema de (...) que cause impacto ambiental, isso cai na mídia e isso faz com que (...) perca na bolsa de valores. (...) não é conveniente deixar que a sociedade e a própria mídia pintem um cenário medonho da empresa no que diz respeito à responsabilidade ambiental. Então ela cuida disso com mais contundência. Há ações governamentais que se desenvolvem e que são elaboradas numa macroescala de abordagem, numa macroescala geográfica de abordagem, onde você tem planos, estratégias muitas vezes são trabalhadas dentro de uma perspectiva mais restrita. ${ }^{(10)}$

O Brasil e a Bolívia dispõem de Instituições governamentais que controlam, de distintas formas e com distintas legislações, a questão ambiental. $\mathrm{O}$ fato de estas instituições pertencerem a Estados diferentes, sem um órgão supranacional que viabilize um diálogo entre as legislações, faz com que não haja um acordo sobre as formas de realizar os controles ambientais na região de fronteira. Cada país possui uma estrutura de legislação ambiental específica, desenvolvida dentro de históricos nacionais distintos, construídas e decididas por atores políticos com interesses diversos. Além desses dois sistemas de

(10) Idem. 
política ambiental, brasileiro e boliviano, intervém a diretriz de desenvolvimento sustentável da IIRSA. A construção das vias de integração da América do Sul — por sua condição internacional — não conta com um organismo de controle ambiental adequado para cálculos de passivos ambientais das obras. Fica difícil, assim, calcular o valor econômico dos impactos e alternativas para a sua mitigação.

\section{A política ambiental boliviana aplicada aOS projetos infraestruturais}

Desde o início dos anos noventa até 2006, os temas em gestão ambiental foram assinados pelo Ministerio de Desarrollo Sostenible (MDS), por intermédio do Viceministerio de Recursos Naturales y Medio Ambiente. Com a Nova Lei de Organização do Poder Executivo (LOPE) e seu Decreto Regulamentar, foi criado o Ministerio de Planificación del Desarrollo (MPD) no lugar MDS.

Assim, grande parte das competências ambientais do então MDS foram distribuídas principalmente entre o Ministerio del Agua, o Ministerio de Desarrollo Rural, Agropecuario y Medio Ambiente e o MPD. Esta estrutura principal vem mudando com a Ley de Autonomías, porém, uma nova estruturação ainda não foi consolidada.

Consequentemente à Lei de Autonomias, essa descentralização nas decisões ambientais tende a aumentar nos próximos anos. O desempenho simultâneo entre tais Ministérios nas decisões ambientais tem gerado algumas indisposições ao longo do tempo como, por exemplo, a definição de quem é a autoridade ambiental competente para emitir licenciamentos ambientais e no que tange à definição de qual deles assumiria os programas que contam com os recursos econômicos de cooperação internacional, como os programas em Mudanças Climáticas (MORALES; ARISMENDI, 2010).

Em 14 de maio de 2007, com a promulgação do Decreto Supremo n. 29.057, resolve-se que a Autoridade Ambiental Competente Nacional é o Viceministerio de Biodiversidad, Recursos Forestales y Medio Ambiente, deixando a cargo do Viceministerio de Planificación Territorial y Ambiental a formulação, execução e coordenação da Planificación Estratégica del Desarrollo y el Ordenamiento Territorial tanto em nível nacional como Departamental e Municipal, participando da planificação estratégica e normas para o Plan del Uso del Suelo (PLUS) "y supervisar el cumplimiento en el marco del desarrollo sostenible y ordenamiento territorial" (Art. 16 da DS n. 25.055: norma complementar ao DS n. 24.855).

Os Departamentos ${ }^{(11)}$ são os responsáveis pela implementação e aplicação do Ordenamento Territorial estabelecido em nível nacional. Formulam o Plano Departamental e dão concordância entre os planos municipais e departamentais de ordenamento territorial.

Toda essa conformação institucional dita formas pelas quais vão funcionar os Estudos de Impacto Ambiental, as auditorias ambientais, esquema este teoricamente sinto-

(11) A Bolívia está dividida em 9 Departamentos: Chuquisaca (capital: Sucre), Cochabamba (Cochabamba), El Beni (ou simplesmente "Beni") (Trinidad), La Paz (La Paz), Oruro (Oruro), Pando (Cobija), Potosí (Potosí), Santa Cruz (Santa Cruz de la Sierra), Tarija (Tarija). 
nizado com a estrutura ambiental de outros países vizinhos. No caso de grandes obras infraestruturais, a avaliação ambiental é dada em caráter federal.

Até a etapa de Estudo de Impacto Ambiental, as estruturas legais brasileiras e bolivianas são semelhantes: são feitos os estudos por uma equipe técnica que emite um relatório à Autoridade Ambiental competente. O que muda é o processo de avaliação do relatório ao licenciamento:

- este estudio de impacto ambiental no va al ministerio aquí en Bolivia: va al organismo sectorial, digamos a al oficina de medio ambiente de Ministerio de Minas. Y la oficina militar del Ministerio de Minas es la que revisa el estudio y lo aprueba y lo manda a la autoridad ambiental, al Ministro de Medio Ambiente para que él lo refrende, lo apruebe, termina de aprobar. O sea, nosotros llamamos aquí "los corderos al lobo". Es el sector minero el interesado que la mina salga adelante que aprueban y que aprueben el estudio de impacto ambiental. Nunca ha habido aquí un caso en que la oficina ambiental minera o hidrocarborífera diga: 'no, no se puede hacer un pozo de explotación petrolera acá porque evidentemente va a afectar una área protegida, un pueblo indígena, etc.'. Nunca ha habido esto. ${ }^{(12)}$

\section{ESTRUTURA MINISTERIAL BOLIVIANA EM MEIO AMBIENTE, COM SUBDIVISÕES}

\begin{tabular}{|c|c|c|}
\hline \multirow[t]{5}{*}{$\begin{array}{l}\text { Ministerio de Planificación } \\
\text { del Desarrollo }\end{array}$} & \multirow[t]{2}{*}{$\begin{array}{l}\text { Viceministerio de Planifica- } \\
\text { ción y Coordinación }\end{array}$} & $\begin{array}{l}\text { Dirección General de Plani- } \\
\text { ficación }\end{array}$ \\
\hline & & $\begin{array}{l}\text { Dirección General de Coor- } \\
\text { dinación Institucional }\end{array}$ \\
\hline & \multirow[t]{2}{*}{$\begin{array}{l}\text { Viceministerio de Planifica- } \\
\text { ción Territorial y Ambiental }\end{array}$} & $\begin{array}{l}\text { Dirección General de Plani- } \\
\text { ficación Territorial }\end{array}$ \\
\hline & & $\begin{array}{l}\text { Dirección General de Plani- } \\
\text { ficación Ambiental }\end{array}$ \\
\hline & $\begin{array}{l}\text { Viceministerio de Ciencia y } \\
\text { Tecnología }\end{array}$ & $\begin{array}{l}\text { Dirección General de Cien- } \\
\text { cia y Tecnología }\end{array}$ \\
\hline \multirow{5}{*}{$\begin{array}{l}\text { Ministerio del Desarrollo } \\
\text { Rural, Agropecuario y Me- } \\
\text { dio Ambiente }\end{array}$} & \multirow{3}{*}{$\begin{array}{l}\text { Viceministerio de Biodiver- } \\
\text { sidad, Recursos Forestales y } \\
\text { Medio Ambiente }\end{array}$} & $\begin{array}{l}\text { Dirección General de Biodi- } \\
\text { versidad y Areas Protegidas }\end{array}$ \\
\hline & & $\begin{array}{l}\text { Dirección General de Me- } \\
\text { dio Ambiente }\end{array}$ \\
\hline & & $\begin{array}{l}\text { Dirección General de Re- } \\
\text { cursos Forestales }\end{array}$ \\
\hline & Viceministerio de Tierras & Dirección General de Tierras \\
\hline & $\begin{array}{l}\text { Viceministerio de Desarrol- } \\
\text { lo Rural y Agropecuario }\end{array}$ & $\begin{array}{l}\text { Dirección General de De- } \\
\text { sarrollo Rural }\end{array}$ \\
\hline
\end{tabular}

(12) Entrevista concedida por Marco Octavio Ribeira Arismendi, diretor da Liga de Defensa del Medio Ambiente de Bolivia (LIDEMA) em 20 de julho de 2010. 


\section{ESTRUTURA MINISTERIAL. BOLIVIANA EM MEIO AMBIENTE, COM SUBDIVISÕES}

\begin{tabular}{|c|c|c|}
\hline \multirow[t]{2}{*}{ Ministerio del Agua } & Viceministerio de Riego & Dirección General de Riego \\
\hline & $\begin{array}{l}\text { Viceministerio de Cuencas y } \\
\text { Recursos Hídricos }\end{array}$ & $\begin{array}{l}\text { Dirección General de Cuen- } \\
\text { cas y Recursos Hídricos }\end{array}$ \\
\hline \multirow[t]{4}{*}{$\begin{array}{l}\text { Ministerio de Relaciones Ex- } \\
\text { teriores y Cultos }\end{array}$} & \multirow[t]{3}{*}{$\begin{array}{l}\text { Viceministerio de Relacio- } \\
\text { nes Exteriores y Cultos }\end{array}$} & $\begin{array}{l}\text { Dirección General de Rela- } \\
\text { ciones Multilaterales }\end{array}$ \\
\hline & & $\begin{array}{l}\text { Dirección General de Rela- } \\
\text { ciones Bilaterales y Cultos }\end{array}$ \\
\hline & & $\begin{array}{l}\text { Dirección General de Lími- } \\
\text { tes, Fronteras y Asuntos Ma- } \\
\text { rítimos }\end{array}$ \\
\hline & $\begin{array}{l}\text { Viceministerio de Relacio- } \\
\text { nes Económicas y Comercio } \\
\text { Exterior }\end{array}$ & $\begin{array}{l}\text { Dirección General de Ne- } \\
\text { gociaciones, Integración y } \\
\text { Acuerdos Comerciales }\end{array}$ \\
\hline $\begin{array}{l}\text { Ministerio de Defensa Na- } \\
\text { cional }\end{array}$ & $\begin{array}{l}\text { Viceministerio de Defensa } \\
\text { Civil y Cooperación al De- } \\
\text { sarrollo Integral }\end{array}$ & $\begin{array}{l}\text { Dirección General de de } \\
\text { Protección al Medio Am- } \\
\text { biente }\end{array}$ \\
\hline
\end{tabular}

Tabela 1: Estrutura Política da Gestão Ambiental Boliviana segundo a LOPE. Elaboração Disponível em: Morales, Arismendi, 2010.

Segundo o Decreto Supremo n. 29.894, de 7 de fevereiro de 2009(13) a temática ambiental é compartilhada entre os Ministérios do Governo. As decisões sobre grandes obras nacionais, desta forma, são analisadas primeiramente por um Setor ambiental de um dos Ministérios envolvidos mais diretamente com a proposta das obras.

De acordo com o grau de envolvimento e interesse pelas obras, os Ministérios intervenientes podem ser: o Ministerio de Planificación del Desarrollo, o Ministerio de Hidrocarburos y Energía, o Ministerio de Desarrollo Productivo y Economía Plural, o Ministerio de Obras Públicas, Servicios y Vivienda, o Ministerio de Minería y Metalurgia e o Ministerio de Desarrollo Rural y Tierras. Comparativamente, os órgãos ambientais do governo boliviano não têm como fazer frente a estes ministérios, pois o setor de energia é visto como prioritário em virtude da significância deste setor à economia do país. No caso de grandes obras infraestruturais nacionais, os principais Ministérios intervenientes são o Ministerio de Planificación del Desarrollo e o Ministerio de Hidrocarburos y Energía.

É neste ponto que se observa como se aplica empiricamente a pouca capacidade de valoração dos recursos naturais de forma estrutural à produção. É valorizada a extração de recursos de forma quantitativa, visando um crescimento econômico. Desconsidera-se, no meio político, a necessidade da estrutura ecossistêmica, de forma qualitativa a alcançar um desenvolvimento econômico.

(13) Decreto Supremo n. 29.894, de 7 de fev./2009. 
Básicamente [o setor de meio ambiente] es el sector que menos importancia tiene, menos presupuesto tiene, que menos gente tiene y es inclusive acudido por la prensa. Nunca la prensa le da opción a un Ministro de Medio Ambiente o Viceministro de Medio Ambiente de hacer una reflexión sobre el sector energético. Siempre habla el sector minero, el sector caminero, etc. Y ahí hay dos figuras: o el ministro del medio ambiente no quiere hablar para no meterse en problemas o la prensa no le abre campo para que salga adelante lo suyo. ${ }^{(14)}$

Em um recorte contemporâneo, outro exemplo de arbitrariedade na tomada de decisões se expressa na polêmica estrada que corta as TIPNIS. Aí, mais uma vez, o mapeamento das reservas hidrocarboníferas neste caso coincide com os parques nacionais e os megaprojetos infraestruturais.

Em relação ao posicionamento do governo boliviano às obras, surge como opinião o autoritarismo do governo de Evo Morales em relação às manifestações da sociedade civil boliviana. Enquanto governo que até então se posicionava numa perspectiva de esquerda, as atuais opiniões tanto de Evo Morales quanto de seu vice, Álvaro Garcia Linera, levam a pensar que tanto a esquerda quanto a direita não chegam a alcançar um modelo efetivamente democrático, oscilando entre ações em prol do desenvolvimento socioambiental e medidas ditatoriais.

Independentemente do fato de parecer que inclusive a esquerda que emerge nos governos possa pensar que seja a única que pode, legitimadamente, promover a mudança na conformação social, política e econômica (muitas vezes, deixando de lado os princípios democráticos), é evidente que o governo boliviano tem encontrado problemas em fazer frente ao imperialismo brasileiro no que diz respeito ao avanço dos investimentos do BNDES $^{(15)}$ e a ação da OAS, neste caso específico das TIPNIS.

Seguindo a análise sobre as instâncias governamentais ${ }^{(16)}$ que legislam sobre o meio ambiente, o Viceministerio de Biodiversidad, Recursos Forestales y Medio Ambiente formula as políticas para desenvolvimento sustentável e, ao mesmo tempo, formula, coordena e executa a legislação para áreas protegidas e gestão ambiental. O órgão responsável pelo acompanhamento das Unidades de Conservação é o Servicio Nacional de Áreas Protegidas (SERNAP). Também estão dentro do MIDRAMA a Superintendencia General del Sistema de Regulación de Recursos Naturales Renovables (SIRENARE), dividida entre os setores de Superintendencia Forestal, que outorga direitos florestais, e a Superintendencia Agraria, que controla o uso da terra.

O Instituto Nacional de Reforma Agrária, por sua vez, se ocupa das titulações das Terras Comunitárias de Origem. O Servicio Nacional de Reforma Agraria é a instância responsável pela distribuição das terras e regulação do saneamento da propriedade agrária.

(14) Entrevista concedida por Marco Octavio Ribeira Arismendi, diretor da Liga de Defensa del Medio Ambiente de Bolivia (LIDEMA) em 20 de julho de 2010.

(15) IIRSA. Origens do IIRSA. Disponível em: <http://www.iirsa.org> Acesso em: 3 mar./2009a.

(16) ASAMBLEA CONSTITUYENTE DE BOLIVIA. Constitución del Estado Plurinacional de Bolivia. Bolivia: El Alto, 2009. Disponível em: <http://www. presidencia.gob.bo/download/constitucion.pdf> Acesso em: 10 abr./2010. 
Grandes projetos de âmbito nacional, ou cuja área de influência envolve mais que um Departamento, têm seu seguimento acompanhado pelos órgãos mencionados nos três últimos parágrafos nos Departamentos. A Constitución Política del Estado de 7 de fevereiro de 2009(17) (CPE, Arts 5f, 108, 109, 110) e o Reglamento General de Áreas Protegidas (DS n. 24.871/1997) delega aos governos dos Departamentos e Municípios a autoridade competente para formular, tomar decisões e executar as ações necessárias para a gestão ambiental.

No caso das municipalidades (CPE, Arts. 200 a 206), duas características se destacam em relação aos Departamentos. A primeira delas é a participação popular na distribuição de recursos (Ley de Participación Popular); a segunda é a transferência aos municípios da tarefa de fiscalização e controle de uso dos recursos naturais (Ley Forestal, 12 de julho de 1996). Municipalmente, as prefeituras se responsabilizam pela aplicabilidade dos Planos de Ordenamento Territorial nacional e departamental e, dentro do que é estabelecido nestas esferas, desenvolve seu Plano Municipal de Ordenamento Territorial e Plano de Uso do Solo (ARNOLD; BARROSO, 2008).

Genericamente, pode-se inferir que a tomada de decisões obedece às determinações dos atores políticos vinculados aos Ministérios que detêm o maior poder decisório, regulado por interesses estratégicos e/ou econômicos. Neste caso, os Ministérios mais fortes são os de Desenvolvimento Agrário e de Minas e Energia.

A mesma evidência se repete no Brasil: tanto em termos numéricos quanto em poder político e encadeamento de interesses governamentais, o Ministério de Minas e Energia e o de Desenvolvimento Agrário possuem um peso muito maior nas decisões que as representações da sociedade civil ou de Ministérios com menor influência política.

No atual contexto de implementação da Lei de Autonomias na Bolívia, pode ocorrer uma complicação neste cenário se a descentralização do poder como desagregador de tais políticas, de forma que se torne inviável a atribuição de responsabilidades em uma escala integrada, como a que pede a gestão dos recursos naturais. Esta é uma questão a ser pensada pelo atual governo e pelos subsequentes em como organizar a estrutura democrática, sem que esta dimensão de interconectividade das autonomias seja perdida.

O plano de desenvolvimento nacional esbarra em uma conjuntura internacional expressa por relações econômicas bilaterais e multilaterais entre o Brasil e a Bolívia ${ }^{(18)}$. Neste aspecto, a conjuntura formada pela a força das empresas construtoras brasileiras, somada à força política e à estrutura ambiental brasileira, menos descentralizada, pode levar a um protagonismo brasileiro em relação à Bolívia na condução das obras.

(17) Constitución del Estado Plurinacional de Bolivia, 2009.

(18) IIRSA. Proyectos Del Eje Peru-Brasil-Bolivia. Proyectos IIRSA. Disponível em: <http://www.iirsa.org/ProyectosEje. asp? CodIdioma=ESP\&Eje=10> Acesso em: 14 jun./2009b; IIRSA. Área de Influencia Proyectos del Eje Peru-Brasil-Bolivia. Disponível em: <http://www.iirsa.org/BancoMedios/Imagenes/mapaperubrasilboliviaarea.jpg> Acesso em: 14 jun./2009c; IIRSA. Princípios orientadores de IIRSA. Disponível em: <http://www.iirs a.org> Acesso em: 14 jun./2009d; IIRSA. Estrutura institucional da IIRSA. Disponível em: <http://www.iirsa.org//Institu cional.asp?CodIdioma=ESP> Acesso em: nov./2010. 
Hay varias [empresas de construtoras às quais foram outorgadas vias de transporte], las más grandes son por ejemplo la OAS, que está con caminos desde al sur de Bolivia [donde] hay un sector indigena y un Parque Nacional y hay un camino que está proyectado que va a cortar entonces la zona más virgen y mejor protegida del sub-andino del pais (...). La [Administradora Boliviana de Carreteras] ABC y el Gobierno a principio están de acuerdo (...) esto va a ser unos 140 millones de dolares que es un crédito de Brasil. Brasil ha puesto la condicionante que para que salga este crédito sea la OAS la empresa que haga el camino, y OAS es una empresa de Brasil que tiene unos antecedentes no solamente en Sudamérica sino también en Brasil: el metro de São Paulo. Es una empresa que ha sido demandada por corrupción, influencia de políticos. [OAS] es una de las más importantes aquí. ${ }^{(19)}$

Desde um ponto de vista de gestão de recursos naturais - o qual, no caso boliviano, está atrelado muito fortemente ao potencial econômico, já que a economia do país gira em torno da extração de minérios - o estabelecimento de políticas e ações de controle de danos ambientais nos territórios nacionais é de crucial importância para que o crescimento econômico seja acompanhado por um desenvolvimento baseado no mínimo impacto a um dado ecossistema.

Todavia, há de se considerar que os Ministérios de Meio Ambiente ${ }^{(20)}$, apesar de existirem para assegurar o cumprimento do zoneamento ambiental nacional, têm menor orçamento na Bolívia e menor poder decisório no governo do Estado. Outros Ministérios mais influentes e com maiores aportes de recursos têm protagonismo nas decisões ambientais, bem como há uma forte influência política dos detentores de grandes extensões de terra.

Diante da forte influência e poder que exercem os latifundiários nos órgãos executivos de ambos os países, as políticas e aplicações ambientais são enfraquecidas no seu poder de decisão dentro da arena política. Essa problemática aparece dentro do poder executivo tanto brasileiro quanto boliviano.

Conclusivamente, e após a análise das forças de ação entre todos os atores governamentais e da sociedade civil envolvidos, podemos inferir que há um panorama bastante delicado, onde interagem projetos de lei e propostas de obras interconectadas que, em uma escala socioambiental, não somente levam a uma perda de biodiversidade, mas inviabiliza a ação da sociedade civil em longo prazo. Os objetivos de expansão de mercado são dissolvidos em diversas propostas "integrativas", regadas à corrupção e descaso; fundamentadas numa falsa promessa de desenvolvimento em um planeta cada vez mais esgotado para a espécie humana. A revisão dos processos decisórios tanto no Brasil como na Bolívia já não é mais somente necessária, como também urgente já que inexiste uma possibilidade de representatividade civil nas decisões governamentais.

(19) Entrevista concedida por Marco Octavio Ribeira Arismendi, diretor da Liga de Defensa del Medio Ambiente de Bolivia (LIDEMA) em 20 de julho de 2010.

(20) MINISTERIO DO MEDIO AMBIENTE Y AGUA. Disponível em: <http://www.mmaya. gob.bo/> Acesso em: jan./2011. 


\section{Referências Bibliográficas}

ESTADO PLURINACIONAL DA BOLÍVIA. DECRETO SUPREMO N. 29.894, DE 7 DE FEVEREIRO DE 2009. Estructura organizativa del Poder Ejecutivo del Estado Plurinacional. La Paz: Palacio de Gobierno de la ciudad de La Paz, 2009.

BOBBIO, Norberto. O Conceito de Sociedade Civil. Rio de Janeiro: Editora Graal, 1982

BORGES, Luciana. Riça. Mourão. Políticas territoriais na fronteira: o Programa de Aceleração do Crescimento e as transformações em Rondônia no início do séc. XXI. Dissertação de Mestrado. São Paulo: Programa de Pós-Graduação em Geografia Humana — FFLCH/USP, 2012.

BRASIL, Senado Federal. O Tratado de Petrópolis e o Congresso Nacional. Brasília: Senado Federal, Gabinete do Senador Geraldo Mesquita Júnior, 2003.

DOMINGUES, César Machado. A comissão de linhas telegráficas do Mato Grosso ao Amazonas e a integração do Noroeste. Anais do XIV Encontro Regional da ANPUH: Memória e Patrimônio. Rio de Janeiro, 2010. ISBN 978-85-60979-08-0. Disponível em: <http://www.encontro2010.rj.anpuh. org/resources/anais/8/1273879829_ARQUIVO_RondonANPUHCesarMachado.pdf> Acesso em: 10 jul./2012.

GOUVEIA, Taciana; DANILIAUSKAS, Marcelo. ABONG: Panorama das Associadas. São Paulo: Publicações ABONG, 2010.

HARVEY, David. A produção capitalista do espaço. São Paulo: Editora Annablume, 2006.

MARTINS JUNIOR, Carlos. Apontamentos para uma leitura de Rondon e da Comissão de Linhas Telegráficas Estratégicas de Mato Grosso ao Amazonas. Tese de Doutorado. São Paulo: Faculdade de Filosofia, Letras e Ciências Humanas da Universidade de São Paulo, 2001.

MORALES, Cécile Belpaire; ARISMENDI, Marco Octavio Ribera. Informe del Estado Ambiental de Bolivia 2007-2008. La Paz: LIDEMA, 2010.

TOCANTINS, Leandro. LX - O Tratado de Petrópolis. In: TOCANTINS, Leandro. Formação histórica do Acre. Vol. II. Rio de Janeiro: Civilização Brasileira; Brasília: INL/Conselho Nacional de Cultura; Rio Branco: Governo do Estado do Acre, 1979, p. 253-275.

VERDUM, Ricardo. Integração, usinas hidroelétricas e impactos socioambientais. Brasília: INESC, 2007. 